Lange, J. de, Deusing, E., Asch, I.F. van, Peeters, J., Zwaanswijk, M., Pot, A.M., Francke, A.L. Factors facilitating dementia case management: results of online focus groups. Dementia: International Journal of Social Research and Practice: 2018, 17(1), 110-125

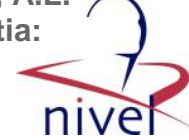

\begin{tabular}{|l|l|}
$\begin{array}{l}\text { Postprint } \\
\text { Version }\end{array}$ & 1.0 \\
\hline Journal website & $\underline{\text { http://dem.sagepub.com/content/early/2016/02/24/1471301216634959.long }}$ \\
\hline Pubmed link & $\underline{\text { http://www.ncbi.nlm.nih.gov/pubmed/26915714 }}$ \\
\hline DOI & $10.1177 / 1471301216634959$ \\
\hline
\end{tabular}

This is a NIVEL certified Post Print, more info at http://www.nivel.eu

\title{
Factors facilitating dementia case management: Results of online focus groups
}

JACOMINE DE LANGE

Program on Aging, Netherlands Institute of Mental Health and Addiction, Utrecht, the Netherlands; Research Centre Innovations in Care, Rotterdam University of Applied Sciences, Rotterdam, the Netherlands

ELINE DEUSING

Program on Aging, Netherlands Institute of Mental Health and Addiction, Utrecht, the Netherlands

IRIS FM VAN ASCH

Program on Aging, Netherlands Institute of Mental Health and Addiction, Utrecht, the Netherlands

JOSÉ PEETERS

NIVEL, Netherlands Institute for Health Services Research, Utrecht, the Netherlands MARIEKE ZWAANSWIJK

NIVEL, Netherlands Institute for Health Services Research, Utrecht, the Netherlands ANNE MARGRIET POT

Program on Aging, Netherlands Institute of Mental Health and Addiction, Utrecht, the Netherlands; Department of Clinical Psychology, EMGO+, VU University Amsterdam, the Netherlands

ANNEKE L FRANCKE $\Uparrow$

NIVEL, Netherlands Institute for Health Services Research, Utrecht, the Netherlands;

Department of Public and Occupational Health, EMGO+, VU University Medical Center Amsterdam, the Netherlands

ANNEKE L FRANCKE, NIVEL, PO BOX 1568, 3500 BN UTRECHT, THE NETHERLANDS.

EMAIL: A.FRANCKE@ NIVEL.NL

\begin{abstract}
To obtain insight into facilitating factors for case management in dementia care, we conducted a qualitative study with 13 online focus groups (OFGs). Participants were professionals involved in dementia case management $(\mathrm{N}=99)$. We used mind-maps and the method of constant comparison for analysis. Participants perceived OFGs as a useful tool to explore their perspectives. The perceived advantage of OFGs was the flexibility and convenience of logging in at any time or place preferred. Five facilitating factors for case management
\end{abstract}


Lange, J. de, Deusing, E., Asch, I.F. van, Peeters, J., Zwaanswijk, M., Pot, A.M., Francke, A.L. Factors facilitating dementia case management: results of online focus groups. Dementia:

were identified in the OFGs: 1. Good cooperation between partners; 2. Organisational embedding with an independent position of case managers; 3 . Structural funding; 4. Competent case managers; 5. Familiarity with case management in the region. Good cooperation was essential for successful dementia case management and should thus be a primary concern for care providers.

\section{INTRODUCTION}

The impact of dementia on society is large and goes beyond the individuals diagnosed with dementia. Particularly for informal caregivers (often partners or other family members) dementia has a huge detrimental impact as well. Informal caregivers are very important in enabling a person with dementia to continue to live at home as long as possible, though they often suffer from a high care pressure and decreased wellbeing (Etters, Goodall, \& Harrison, 2008; Pinquart \& Sorensen, 2003, 2007). Therefore, availability of high-quality support for both people with dementia and their informal caregivers is needed, which requires integrated and coordinated dementia care services (World Health Organisation (WHO), 2008). Case management is in many countries (e.g. France, Hong Kong, India, the Netherlands, UK, US) a strongly promoted intervention. However, the organisation and implementation vary and access to case management is influenced by funding policies and cultural variations (Reilly et al., 2015). The focus of case management differs, in some cases the focus is on supporting the person with dementia and the family carers, often for a longer period (Chien \& Lee, 2008; Judge et al., 2011), in other cases on appropriate delivery of services in the short term (Lam et al., 2009) or in the long term (Callahan et al., 2006; Chu, Edwards, Levin, \& Thomson, 2000; Eloniemi-Sulkava et al., 2009).

In The Netherlands, case management focuses on supporting both the person with dementia and the family, as important part of integrated regional supply of dementia care. The Dutch government, in cooperation with, amongst others, the Dutch Alzheimer's Association, has promoted the close collaboration between dementia care providers within regional dementia care networks for around a decade (Ministry of Health, Welfare and Sports, Zorgverzekeraars Nederland, Alzheimer Nederland, ActiZ, 2009). One of the main tasks of these regional networks is to organise case management, which is defined as 'systematic provision of coordinated care and support in treatment, health and social care, by a permanent professional, who is part of a regional network aimed at community-dwelling people with dementia and their family during the whole trajectory from (suspected) diagnosis until institutionalisation or death or even beyond" (Alzheimers' Netherlands/Vilans, 2013). Considering the fact that the number of dementia case management initiatives is increasing, we wanted more insight into factors facilitating case management. Therefore, the primary objective of this paper is to give insight into such factors, from the perspectives of involved professionals.

The secondary objective of this paper is to give insight into the usefulness of online focus groups (OFGs) in the study population. We chose to use OFGs primarily for practical reasons: we wanted to include professionals from regional networks all over the country. 
Lange, J. de, Deusing, E., Asch, I.F. van, Peeters, J., Zwaanswijk, M., Pot, A.M., Francke, A.L. Factors facilitating dementia case management: results of online focus groups. Dementia: International Journal of Social Research and Practice: 2018, 17(1), 110-125

To attain an optimal participation rate, the online mode of the focus groups had several advantages. A recent study (Zwaanswijk \& van Dulmen, 2014) showed that most OFG participants highly value the convenience of participating in an OFG in their own preferred time and place. A second advantage of using OFGs is the fact that the written contributions of participants yield immediately available data, which considerably decreases costs and time needed for data entry and analysis (Tates et al., 2009). Moreover, previous research has shown that the anonymity in OFGs allows participants to speak more freely, particularly regarding sensitive topics (Joinson, 2001; Montoya-Weiss, Massey, \& Clapper, 1998; Reid \& Reid, 2005; Walston \& Lissitz, 2000). This may also be an advantage in this study population. Hence, this paper also addresses the usefulness of OFGs as perceived by the professionals involved in dementia case management.

\section{METHOD}

Setting This study involved professionals from 13 regional networks for dementia care. These 13 networks form a convenience sample of a total of about 70 regional dementia care networks in The Netherlands. The networks concern formal regional alliances of relevant inpatient and outpatient care providers, including home care organisations, nursing homes, elderly care homes, general practices, welfare organisations and community mental health centres. An important function of a network is to provide case management to people with dementia and their informal carers. Project coordinators of the 13 dementia care networks signed in for participation in the study, answering an open call from the Dutch Alzheimer Association. In the study period (2010/2011), one of the regional networks had a relatively long experience with organising case management (since 1995), seven networks had started with case management between 2003 and 2008, while five others more recently started offering case management (since 2009 or 2010).

\section{Case management interventions}

Seven of the participating networks deliver case management only when there is a formal diagnosis of dementia, while case management may already start in the prediagnosis stage in the other six networks. However, the general approach of the case manager is the same. In all participating networks the case managers - nurses or social workers specialised in dementia care - act as a central, trusted contact person, guiding patient and family through the process of care. The case manager provides information about dementia and options for professional support, gives practical advice and social and emotional support to the person with dementia and the informal caregiver, until admission in a nursing home or other facility (Peeters et al., 2013). Face to face contacts (mainly at home) are often combined with email or telephone contacts. The frequency of contacts is guided by the needs of the people with dementia and their informal carers.

\section{Sample}

The project coordinators of the participating regional networks recruited professionals from their network to participate in an OFG. We asked the project coordinators to select in their regional network a sample of 10 to 15 professionals involved in case management, who varied in professional background (purposive sampling). This resulted in an initial sample of 146 professionals. The research team sent these professionals information about the project by email, and an invitation to 
Lange, J. de, Deusing, E., Asch, I.F. van, Peeters, J., Zwaanswijk, M., Pot, A.M., Francke, A.L. Factors facilitating dementia case management: results of online focus groups. Dementia:

participate in an OFG in their own region. Ninetynine professionals $(68 \%)$ accepted this invitation. The composition in occupation differed between OFGs (Table 1).

\section{[TABLE 1]}

\section{Data collection}

Thirteen OFGs were organised between October 2010 and October 2011 (one OFG for each participating regional dementia care network). The OFGs were conducted using a web-based application that was developed as part of previous research (Tates et al., 2009; Zwaanswijk et al., 2007). Participants received an e-mail with an individual login name and password, with which they could anonymously access the OFG application for two weeks. This e-mail offered information about the research project and the OFGs and emphasized the voluntariness and anonymity of the participation. The OFGs were conducted in an asynchronous form (Montoya-Weiss et al., 1998; Rezabek, 2000), meaning participants could log in, read others' comments and respond, at any time within the two week period. The researchers acted as moderators and concealed any personal details if these were posted by the participants. In the interest of clarity, the professional occupation of each participant was displayed to other participants. We developed the first draft of the topic guide with discussion questions and statements before the start of the OFGs. Further development and fine tuning of the topic guide was done during the cyclic process of data collection and analysis. Examples of questions and statements are: Which organisational conditions are needed to structurally embed case management in your region?; Case management can best be provided by case managers who have ties with different organisations; Only after a supplemental training in case management, a new case manager can do the job adequately. We posted questions and statements on day 1, 5, 9 and 12. When new questions and statements were posted, participants received an e-mail. When activity of participants in the discussion was low, we sent reminders asking participants to reply to statements, as well as to each other. Two authors (IA and JL) acted as moderators by regularly checking the postings and posting new questions and statements. All typed replies were automatically transferred to the dataset with transcriptions.

At the end of the OFG participants could answer an open question about their participation. In addition, a few days after the end of each OFG we sent the participants a short online questionnaire to evaluate this method. The questionnaire was based on literature on the advantages and disadvantages of OFGs (e.g. Reid \& Reid, 2005), and was developed as part of a larger study about the advantages of online and face-to-face focus groups (Zwaanswijk \& van Dulmen, 2014). The evaluation questionnaire started with a question regarding the preference for participation in an OFG or a face-to-face focus group (FTF). Respondents were subsequently asked to rate on a predetermined list which advantages they perceived of participating in OFGs or face-to-face focus groups, respectively. They could also fill in any additional advantages. Respondents who preferred to participate in an OFG were asked to indicate the advantages of the online mode, whereas respondents who expressed a preference for participation in FTF were asked to indicate the perceived advantages of that method. Respondents who expressed no preference for either OFGs or FTFs were requested to rate the advantages of both methods. The remaining evaluation questions addressed the duration of the OFGs, and whether or not to introduce all questions at the start of the OFG. 
Lange, J. de, Deusing, E., Asch, I.F. van, Peeters, J., Zwaanswijk, M., Pot, A.M., Francke, A.L. Factors facilitating dementia case management: results of online focus groups. Dementia:

\section{Data analysis of the online discussions}

An eclectic inductive method was used, inspired by grounded theory and thematic analysis to analyse the transcripts of the OFGs. Techniques of open coding, memo writing and constant comparison were used, which are common in both thematic analysis and grounded theory (Braun \& Clarke, 2006; Strauss \& Corbin, 1990). Using the software programme MaxQDA, two researchers (IA and JL) analysed the transcripts of all OFGs, initially independently.

We used pre-designed codes (related to our primary research objective), and created new codes during the open coding process, directly based on the transcripts. Disagreements in the initial analyses were discussed until consensus was reached. Subsequently, we selected and restructured codes about facilitating factors by formulating categories of a higher abstraction level. Both the selection of relevant codes and the categorisation were performed and discussed jointly (by ED and JL). This resulted in eight initial categories of facilitating factors. We analysed and recoded data in these eight categories per category with more specific codes and used the method of constant comparison during analysis; fragments with the same code were compared with regard to similarities and differences (Lingard, Albert, \& Levinson, 2008). To structure thoughts and to create a clear view of the category, we drew mind-maps and discussed those maps until consensus was reached (ED and JL). During analysis, the eight initial categories were restructured into five categories (five facilitating factors) with subcategories. By returning to the original data we checked mind-maps and coding. During the process of analysis we made use of conceptual and theoretical memos. Results were discussed with the research group (peer review).

\section{Analysis of the data of evaluation questionnaire}

Using the statistical package STATA, descriptive statistics (percentages and frequencies) were counted for the analyses of the data of evaluation questionnaire.

\section{Ethics}

Participants received written information about the aim and content of the study in an information letter preceding their participation in the OFG. The anonymity of the participants was strictly safeguarded throughout the process of data collection and analysis. Further ethical approval of this study was not required under the applicable national Dutch legislation (http://www.ccmo.nl/en/), since all participants were competent individuals and this study did not involve any interventions or treatments.

\section{Findings}

The first objective was to obtain insight into factors influencing the success of case management in dementia care. Based on the analysis of the OFGs with case managers and other professionals involved, we identified five main facilitating factors for the implementation of dementia case management: Good cooperation between partners; Organisational embedding with an independent position of the case manager; Structural funding; Competent case managers; Familiarity with case management in the region.

\section{Good cooperation between partners}

The professionals found cooperation between partners in their regional network a prerequisite for offering sound dementia case management. Through cooperation 
Lange, J. de, Deusing, E., Asch, I.F. van, Peeters, J., Zwaanswijk, M., Pot, A.M., Francke, A.L. Factors facilitating dementia case management: results of online focus groups. Dementia: International Journal of Social Research and Practice: 2018, 17(1), 110-125

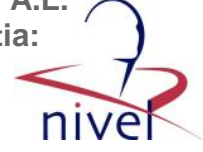

they were able to promote integration of care and to meet the needs of the people with dementia and their informal caregivers.

The willingness of care organizations not to act from a profit perspective but from the perspective of the needs of people with dementia is important. How can we finetune the care together so that the person with dementia has actually been helped? (Mental health nurse) Additionally, the professionals indicated that proper cooperation can facilitate commitment to and support for case management amongst partners of the dementia care network. Case managers themselves can also facilitate cooperation. They can play an active role in linking stakeholders and promoting case management to network partners in particular to the general practitioner. Good cooperation exists of the following four aspects, according to the professionals: agreements clarifying mutual expectations, easy referrals and direct contacts, transparency and reciprocity, and cooperation on different levels.

\section{Agreements with the network partners clarifying mutual expectations.}

Professionals indicated that making, detailing and honouring agreements with the network partners, collected in a care programme document, was important. Arrangements concerning the allocation of tasks amongst cooperating partners and the job content of case managers were deemed particularly necessary. In addition, they found organisational arrangements necessary, e.g. regarding the route of referrals and inter-professional consultations about referrals. By making these agreements, mutual expectations of cooperation partners became realistic and clear. Absence of competition between organisations was helpful in this case.

Easy referrals to case management and direct contacts. The participating professionals recommended regular consultation between case managers and general practitioners who often make referrals to case management. They also mentioned the option to set up a central regional point for the applications for case management. This would make the route of referral clear and case management easy to find for general practitioners and other professionals. However, centralising applications could hinder direct contact between case managers and other professionals of the care organisations in the network, because of the formation of a new institution between the other organisations. Direct contact between case managers and other professionals was considered very important for a smooth and swift referral of clients and for attuning to changing needs of the client.

Transparency and reciprocity in communication. Professionals regarded open and transparent communication and exchange of information between the case manager and other professionals a main condition for good cooperation. To achieve this, they found reciprocity important: the case manager has to keep partners within the regional network informed and network partners have to give feedback to the case manager. Professionals also indicated that multidisciplinary consultation, care-plan consultations, casuistry discussion, and informal consultations were facilitators of transparency in communication. Some professionals preferred the use of pre-existing structures, e.g. allowing case managers to use the general practitioner's electronic medical records.

Broad cooperation within the network on different levels. Intensive cooperation between primary health care professionals, especially between general practitioners and case managers, and between primary and secondary healthcare professionals is required in the dementia care networks. 
Lange, J. de, Deusing, E., Asch, I.F. van, Peeters, J., Zwaanswijk, M., Pot, A.M., Francke, A.L. Factors facilitating dementia case management: results of online focus groups. Dementia:

We need clear collaboration agreements between care providers in the dementia care network, between general practitioner and case manager, but also between specialist in geriatric medicine or psychologist and case manager. Unfortunately, there is a lot of competition between care providers. (Case manager) The importance of good cooperation with various care organisations in the network and with municipal policy-makers was also mentioned. Furthermore, the expansion of the dementia care networks to not yet conventionally involved informal care organisations, and welfare and care administration offices was thought to improve the chance of successful implementation of case management.

\section{Organisational embedding with an independent position of case managers}

The professionals also considered organisational embedding of the case manager as very important for the implementation of case management. The position of case managers within the dementia care network can impact the independency of case managers. Since case management should match the needs of the person with dementia, only the interests of the client and not the interest of the organisation to which case managers belong should influence them. Organisational embedding is thus intertwined with the independence of the case manager, and can affect the freedom of choice and choice options of the client. It is therefore important to reflect on the advantages and disadvantages of different ways of organisational embedding of case management before it can be structurally implemented.

Important facilitators of the independence of case managers are supervision and coaching, transparent working arrangements between the network partners and the absence of competition. The following three ways of organisational embedding were distinguished: multiple providers, an independent organisation for case management, and one broad care organisation providing case management in the region.

Multiple providers of case management. An important benefit of multiple providers is the variety in expertise and background of the different organisations, according to the professionals.

This variety increases choice options of the client and creates a wide breadth of knowledge and expertise within the network of case managers. This allows case managers to learn from each other, which can improve the quality of their work. Another advantage is that case managers directly work with various disciplines. Since case management is broad, you have to be familiar with lots of things like home care, living arrangements and welfare. Thus, it is very desirable for different organisations to work together.

Together, you'll know more! (Case manager) As long as we all share the same goal, it does not matter if there are multiple organizations. I can make use of the expertise of other organizations. And for the customer, there is always one's own free choice. (Geriatric nurse) However, some participants also emphasized that there may also be disadvantages of multiple health care providers: the independence of the case manager can be compromised. Competition can instigate organisations to pressure their "own" case manager to refer clients to their own care institute. However, this pressure was perceived differently by case managers participating in the OFGs, even within the same regional dementia care network. Some perceived pressure, others did not.

Another disadvantage of multiple health care providers the professionals mentioned is that there is no central point to contact case managers. In addition, each organisation has its own way of doing things and would like to keep it that way. This 
Lange, J. de, Deusing, E., Asch, I.F. van, Peeters, J., Zwaanswijk, M., Pot, A.M., Francke, A.L. Factors facilitating dementia case management: results of online focus groups. Dementia:

can create diversity in the execution of case management and, consequently, confusion about responsibilities and job content of case managers. Also, continuity of case management can be jeopardised if organisations themselves determine whether they offer or cease to offer case management, for reasons such as lack of funding.

An independent organisation of case managers. The professionals expected case managers to attain the largest extent of independency when case management is employed by an independent organisation. This organisation should have no interest in referring clients to a particular organisation. Therefore, no pressure from organisations on case managers is expected, and the client's needs will remain the primary concern. Because case managers would be centred in one organisation, communication and uniform execution of case management should become easier. However, the professionals considered a lack of multidisciplinarity as a potential disadvantage of this form of organisation of case management. Additionally, a case manager expected ". . . case management to become a separate fragment, while connections [to other professionals] become very short." A solution could be an organisation consisting of case managers with a wide professional background, creating a broad body of knowledge within the organisation. "Another possibility is forming an independent organisation when the cooperation [between network partners] is stable and successful', a psychologist mentioned.

One broad care institute providing case management. Some professionals preferred case management to be provided by only one organisation in the network. Perceived benefits were: uniform care process and clear referrals.

\section{Structural funding}

Structural financing was deemed a prerequisite to successfully implementing case management. Networks used various funding resources: funding from project grants as well as funding received from national health care insurances. The professionals reported some obstacles of the various ways of financing: funding from project grants is always a temporary source of financing, while funding gained from health care insurances can only be gained under rather strict conditions and is sometimes difficult to obtain. Therefore, the professionals considered it important to have funding that is clear in advance and makes case management publicly accessible. It would be nice that you did not have to think about funding every time you are delivering care.

As a professional you should offer the right care at the right time in the right place, independently of the right funding. (Case manager) Additionally, structured financing should offer continuity, doing justice to the sustainable nature of case management and perpetuating the relationship between case manager and client that is already established.

To reduce silo's within integrated dementia care, it is obvious that the most functional and workable way of financing case management should be a single source of funding. This would require a specific form of funding in which all different stages of the disease process with the various financing channels are included. Given the mergers and financial position of municipalities at the moment, structurally. 
Lange, J. de, Deusing, E., Asch, I.F. van, Peeters, J., Zwaanswijk, M., Pot, A.M., Francke, A.L. Factors facilitating dementia case management: results of online focus groups. Dementia:

\section{Competent case managers}

Professional considered a basic level of knowledge and skills of case managers important, because then quality of case management can be guaranteed. This is crucial, because persons with dementia often have complex care needs during the course of dementia, in which comorbidity, psychiatric, somatic and social problems are present. A basic profile of competencies and expertise that case managers should master at a minimum was put forward: - communication skills enabling case managers to deal with different people with dementia, informal carers and professionals, - a proactive style of work, - the ability to reflect on their behaviour and knowledge of their own limits, - analytical capabilities to analyse complex care situations, - and excellent expertise in dementia and informal care.

Additionally, the case manager should possess coaching, assisting and advisory skills, also in relation to other care providers, and should be able to work in a multidisciplinary team.

Case managers with a proactive, solution-oriented work style that look after and defend the interests of clients with enthusiasm were valued. Also, the case manager is often selfemployed; therefore, it was considered important that case managers can reflect on their behaviour and understand the consequences, and know the limits of their abilities. In addition to an appropriate bachelor degree, some professionals deemed additional training necessary or desirable; others considered working experience in elderly care, outpatient care or dementia health and social care sufficient.

'My opinion is that a bachelor is a must. Within a team, it makes sense to have diversity. Case managers with different education can reinforce each other, grow and thus increase their expertise.' (network coordinator) 'A bachelor in Nursing is a good basis, especially considering the nursing knowledge. But experience shows that there are some other important core qualities that you cannot learn during a college nursing education. You can't learn the right attitude and feeling with dementia from a book. Either you have it, or you don't have it.' (Case manager) Post-bachelor case management training and/or training in dementia care provides the advantage of case managers meeting a standardised quality level. The importance of maintaining levels of expertise and skills by coaching, peer review, training and attending symposia was also acknowledged. The advantage of joint training in the regional dementia care networks, in whatever form, is that uniformity of case management will be enhanced.

\section{Familiarity with case management in the region}

Participants emphasized the importance of GPs and other professionals within the specific region being familiar with the available case management supply. They considered this necessary for promoting referrals and cooperation. As a case manager mentioned: 'Clients are referred by GPs most of the time. We work together closely with a number of them.

Others refer less often. They do not seem to be fully aware of the opportunities and benefits of case management.' On the other hand, other people also have to be familiar with case management, as a geriatrician explained: "High-quality screening of dementia could be promoted by making case management widely known not only to professionals but also amongst volunteer-based and welfare organisations and Alzheimers' cafe' s." Satisfaction of the participants with the online focus group (OFG) methodology 
Lange, J. de, Deusing, E., Asch, I.F. van, Peeters, J., Zwaanswijk, M., Pot, A.M., Francke, A.L. Factors facilitating dementia case management: results of online focus groups. Dementia:

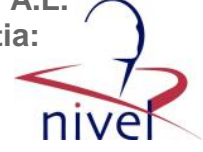

As said, the secondary objective of this paper is to provide insight into whether the OFG methodology is also useful in research amongst dementia care professionals. A total of 34 of the 99 OFG participants completed the short evaluation questionnaire after the closing of the OFGs, and 27 participants answered the open question about how they appraised the participation in the OFG. The latter data were used to illustrate the results of the questionnaire. When asked whether they preferred to participate in an OFG or an FTF, 56\% of respondents expressed a preference for participation in an OFG, $20 \%$ even stated that they would not have participated in a FTF. One-third (35\%) preferred to participate in an FTF, and $9 \%$ had no specific preference.

The most frequently mentioned advantage of OFGs was the convenience of participating in his or her own time and from the own home (Table 2). Anonymity was also mentioned as an advantage of OFGs, although some participants noted that they could easily identify the other participants.

Almost all participants liked the participation in the OFG. 'I am pleasantly surprised by this way of data-gathering. I liked reading others' opinions' a project leader responded.

Some say they are going to use this way of data collection for their own future studies.

Others emphasized having learned from the remarks from the other professionals. A general practitioner noted: 'An OFG can be a good preparation for a regional policy meeting.' The most frequently mentioned disadvantage of the OFGs was that it sometimes limited inter-participant exchange. A number of participants visited the website only once and therefore could respond to previous respondents but not to those who logged in after them. Forty percent of respondents found the given time to respond (two weeks) too short. They also noted that OFGs are less compulsory than FTFs. The respondents suggested making the login time longer and to send an automatic reminder half way or when new comments were placed.

\section{[TABLE 2]}

\section{DISCUSSION}

\section{Factors facilitating case management}

The first objective of this paper was to give insight into factors facilitating dementia case management, from the perspectives of professionals involved. Professionals stated five facilitating factors for dementia case management: good cooperation between care network partners, taking into account the advantages and disadvantages of different ways of embedding case management in the regional dementia care network, clear and structural funding, competent case managers and familiarity with case management within the network. The professionals had different views about the exact details of these prerequisites and they mentioned the lack of uniformity as a barrier of clear formulation of case management. This might be a consequence of the Dutch bottom-up healthcare policy, but also Barnford et al. (2014) describe in a study performed in the UK, uncertainty about scope and aims of case management and lack of clarity of case management roles, as barriers to implementation. The dementia care networks that participated in this study were diverse in their experience with case management (between one and 15 years of experience with 
Lange, J. de, Deusing, E., Asch, I.F. van, Peeters, J., Zwaanswijk, M., Pot, A.M., Francke, A.L. Factors facilitating dementia case management: results of online focus groups. Dementia:



case management) and were experimenting with integrated care cooperation, tuning mutual goals, establishing content of care, and laying down agreements; characteristics of the experiment and implementation phase of a care network (Minkman, Ahaus, \& Huijsman, 2009). In this stage, it is important to exchange information about organisational working methods, expertise and skills and to evaluate initiatives, after which adjustment can take place (Minkman et al., 2009). To allow the care networks to achieve integrated care, a certain level of uniformity is required, according to the professionals. Increased uniformity will clarify expectations, possibilities and limits of the case manager, which facilitates cooperation between case manager and care partners.

Good cooperation between care network partners is considered to be a key factor for positive outcomes of case management, and is associated with close contact with family physicians, transparent referral systems, regular meetings and web based tracking systems (Khanassov, Vedel, \& Pluye, 2014).

Embedding of case management in the local dementia care networks has been identified as a key factor for success in other studies (Minkman et al., 2009; Somme et al., 2012; Verkade et al., 2010). It might be difficult for case managers to take responsibility for the wider dementia care network, as they might focus more on their own organisation (Callahan et al., 2006; Chien \& Lee, 2008; Lam et al., 2009). Embedding them organisationally within the broader network might positively affect the implementation of case management.

In addition, competencies that a case manager should possess can be formulated more sharply. Professional background as a nurse or social worker might make professionals competent to act as case manager. However, advanced practice and continuing special education in dementia care are often considered as prerequisites (Barnford et al., 2014; Reilly et al., 2015).

In general, inter-disciplinary and inter-sectoral cooperation, and implementation of changes in organisation of health care are challenging and complex (Grol, Bosch, Hulscher, Eccles, \& Wensing, 2007; Koelen, Vaandrager, \& Wagemakers, 2008). Funding and collaboration were found to be major facilitators for innovations in health care; regulation and reimbursement structures were found to be barriers. Open communication, interpersonal relations and networks, and close connections between innovators and mainstream businesses are frequently promoted as necessary criteria for innovating (Varkey, Horne, \& Bennet, 2008). Plans for change should be based on evidence and barriers and facilitators to change (Grol \& Grimshaw, 2003). This study gives detailed guidance in doing so from the perspective of professionals.

\section{Reflections on the OFGs method}

Our secondary objective was to gain insight into whether OFGs were useful in research amongst dementia care professionals who were collaborating in a care network. The overall conclusion is that OFGs are a feasible tool in this group. We found some remarkable differences with findings from previous OFGs (Zwaanswijk \& van Dulmen, 2014). Whereas almost all of our participants perceived the anonymity of OFGs as an advantage (95.5\%) and $95.5 \%$ indicated to find it easier to discuss personal issues through the Internet. These issues were mentioned considerably less frequently as an advantage of OFGs by adults in a previous study (19.4\% and $11.4 \%$, respectively) (Zwaanswijk \& van Dulmen, 2014). The first difference may be explained by the fact that our participants were collaborating in 
Lange, J. de, Deusing, E., Asch, I.F. van, Peeters, J., Zwaanswijk, M., Pot, A.M., Francke, A.L. Factors facilitating dementia case management: results of online focus groups. Dementia: International Journal of Social Research and Practice: 2018, 17(1), 110-125



care networks and that they knew each other. The suggestion of one participant to use an OFG as preparation for a regional policy meeting underlines this.

$81.8 \%$ of our participants said that they could better express their answers when writing down.

We have chosen to use OFGs to accommodate the professionals' busy schedules, thereby aiming to lower the threshold of participation, necessary to attain a diverse sample. This aim was reached, since a total of 99 professionals participated in the OFGs, representing 11 different professions, and in every OFG at least three different professions were present.

The representation of different professions within the OFGs underlines the legitimacy of our results. The choice to use the online mode was also a strength from the perspective of the majority of the participants. This is, amongst others, illustrated by the fact that the majority preferred the online mode, and about one in five respondents stated that that they would not have participated in a traditional FTF. However, a disadvantage of OFGs is that it is difficult to stimulate a lively discussion, particularly if participants log in infrequently.

This was also concluded in the paper of Zwaanswijk and van Dulmen (2014). In such situations, participants often do respond to questions of the moderators. Moderators may anticipate this by being more active through summarizing previous responses and inviting other participants to respond.

\section{CONCLUSION}

This paper shows that for successful implementation of case management, attention should be given to cooperation between partners within a dementia care network, which is not as easy as it seems to be. Good cooperation between network partners is essential for successful dementia case management and should thus be a primary concern for the regional dementia care networks. Attention should also be given to more clearly defining the tasks of the case manager and creating uniformity in the organisation of case management. However, a uniform organisation does not mean that interventions of all case managers must be the same: the strength of case management lies in its client-centred approach and nonstandardised intervention, and diversity in case management is valuable in regard to choice options of the client. In addition, the paper shows that OFG methodology is appropriate for exploring perspectives of professionals working in dementia care. The most frequently mentioned advantage of OFGs was the flexibility and the possibility of logging in at his or her preferred place and time. However, a prerequisite is that focus group moderators actively stimulate discussions, by regularly summarizing responses and inviting participants to respond to each other.

\section{ACKNOWLEDGEMENTS}

We thank Julie Meerveld of the Dutch Alzheimer Association for her valuable comments on the draft and execution of the study Authors' contribution JL, AF, JP and AMP were responsible for the design of this study. JL, ED and IA performed the analyses, advised by AF, JP, MZ and AMP. JL drafted the manuscript in cooperation with all other co-authors . 
Lange, J. de, Deusing, E., Asch, I.F. van, Peeters, J., Zwaanswijk, M., Pot, A.M., Francke, A.L. Factors facilitating dementia case management: results of online focus groups. Dementia: International Journal of Social Research and Practice: 2018, 17(1), 110-125

\section{DECLARATION OF CONFLICTING INTERESTS}

The author(s) declared no potential conflicts of interests with respect to the research, authorship, and/ or publication of this article.

\section{FUNDING}

The author(s) disclosed receipt of the following financial support for the research, authorship, and/or publication of this article: ZonMw-NPO (the National Care for the Elderly Programme of the Netherlands Organisation for Health Research and Development).

\section{REFERENCES}

Alzheimers' Netherlands/Vilans. (2013). Zorgstandaard Dementie [The national standard for dementia care] (in Dutch). Amersfoort: Alzheimers' Netherlands.

Barnford, C., Poole, M., Brittain, K., Chew-Graham, C., Fox, C., lliffe, S., Manthorpe, J., . . . Robinson, L. (2014). Understanding the challenges to implementing case management for people with dementia in primary care in England: A qualitative study using Normalization Process Theory. BMC Health Service Research, 14, 549.

Braun, V., \& Clarke, V. (2006). Using thematic analysis in psychology. Qualitative Research in Psychology, 3, 77-101.

Callahan, C. M., Boustani, M. A., Unverzagt, F. W., Austrom, M. G., Damush, T. M., \& Perkins, A.

J. (2006). Effectiveness of collaborative care for older adults with Alzheimer disease in primary care: A randomized controlled trial. Journal of American Medical Association, 295, 2148-2157.

Chien, W. T., \& Lee, Y. M. (2008). A disease management program for families of persons in Hong Kong with dementia. Psychiatric Services, 59, 433-436.

Chu, P., Edwards, J., Levin, R., \& Thomson, J. (2000). The use of clinical case management for early stage Alzheimer's patients and their families. American Journal of Alzheiemer's Disease and Other Dementias, 15, 284-290.

Eloniemi-Sulkava, U., Saarenheimo, M., Laakkonen, M. L., Pietila“ , M., Savikko, N., Tilvis, R. S., Pitka" la", K. H.,. . . Kautiainen, H. (2009). Family care as collaboration: Effectiveness of a multicomponent support program for elderly couples with dementia: Randomized controlled intervention study. Journal of the American Geriatric Society, 57, 2200-2208.

Etters, L., Goodall, D.,\&Harrison, B. E. (2008). Caregiver burden among dementia patient caregivers:A review of the literature. Journal of the American Academy of Nurse Practice, 20, 423-428.

Grol, R., \& Grimshaw, J. (2003). From best evidence to best practice: effective implementation of change in patients' care. The Lancet, 362, 1225-1230.

Grol, R. R. P. T. M., Bosch, M. M. C., Hulscher, M. M. E. J. L., Eccles, M. P., \& Wensing, M. (2007).

Planning and studying improvement in patient care: The use of theoretical perspectives. The Milbank Quarterly, 85, 93-138.

Joinson, A. N. (2001). Self-disclosure in computer-mediated communication: The role of selfawareness and visual anonymity. European Journal of Sociology and Psychology, 31, 177-192.

Judge, K. S., Bass, D. M., Snow, A. L., Wilson, N. L., Morgan, R., Looman, W. J., McCarthy, C., ... Kunik, M. E. (2011). Partners in dementia care: A care coordination intervention for individuals with dementia and their family caregivers. The Gerontologist, 51, 261-272. Koelen, M. A., Vaandrager, L., \& Wagemakers, A. (2008). What is needed for coordinated action for health? Family Practice, 25(suppl. 1): i25-31.

Khanassov, V., Vedel, I., \& Pluye, P. (2014). Barriers to implementation of case management for patients with dementia: A systematic mixed studies review. Annals of Family Medicine, 12, 456-465. 
Lange, J. de, Deusing, E., Asch, I.F. van, Peeters, J., Zwaanswijk, M., Pot, A.M., Francke, A.L. Factors facilitating dementia case management: results of online focus groups. Dementia: International Journal of Social Research and Practice: 2018, 17(1), 110-125

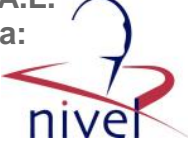

Lam, L. C. W., Lee, J. S. W., Chung, J. C. C., Lau, A., Woo, J., \& Kwok, T. C. Y. (2009). A randomized controlled trial to examine the effectiveness of case management model for community dwelling older persons with mild dementia in Hong Kong. International Journal of Geriatric Psychiatry, 25, 395-402.

Lingard, L., Albert, M., \& Levinson, W. (2008). Grounded theory, mixed methods, and action research. British Medical Journal, 7, 337:a567.

Ministry of Health, Welfare and Sports, Zorgverzekeraars Nederland, Alzheimer Nederland, ActiZ.

(2009). Leidraad Ketenzorg Dementie [Guiding tool to develop a multi-disciplinary network for dementia care] (in Dutch). The Hague: VWS.

Minkman, M. M. N., Ahaus, K. T. B., \& Huijsman, R. (2009). A four phase development model for integrated care services in the Netherlands. BMC Health Services Research, 9, 42.

Montoya-Weiss, M. M., Massey, A. P., \& Clapper, D. L. (1998). On-line focus groups: Conceptual issues and a research tool. European Journal of Marketing, 32, 713-723.

Peeters, J. M., de Lange, J., van Asch, I., Spreeuwenberg, P., Veerbeek, M., Pot, A. M., . . . Petrea, I.

(2013). Improving dementia care worldwide: Ideas and advice on developing and implementing a National Dementia Plan. London: Bupa/ADI.

Pinquart, M., \& So" rensen, S. (2003). Differences between caregivers and noncaregivers in psychological health and physical health: A meta-analysis. Psychology and Aging, 18, 250-267.

Pinquart, M., \& So" rensen, S. (2007). Correlates of physical health of informal caregivers: A meta-analysis. Journal of Gerontology B Psychological Sciences Sociological Sciences, 62, 126-137.

Reid, D. J., \& Reid, F. J. M. (2005). Online focus groups: An in-depth comparison of computermediated and conventional focus group discussions. International Journal of Market Research, 47, 131-162.

Reilly, S., Miranda-Castillo, C., Malouf, R., Hoe, J., Toot, S., Challis, D., . . Orrell, M. (2015). Case management approaches to home support for people with dementia (Review). The Cochrane Library, 1, 1-182.

Rezabek, R. (2000). Online focus groups: Electronic discussions for research. Forum Qualitative Sociological Research, 1, 18.

Somme, D., Trouve, H., Drame' , M., Gagnon, D., Couturier, Y., \& Saint-Jean, O. (2012). Analysis of case management programs for patients with dementia: A systematic review. Alzheimer's \& Dementia, 8, 426-436.

Strauss, A., \& Corbin, J. (1990). Basics of qualitative research: Grounded theory procedures and techniques. London: Sage.

Tates, K., Zwaanswijk, M., Otten, R., van Dulmen, S., Hoogerbrugge, P. M., Kamps, W.

A., ... Bensing, J. M. (2009). Online focus groups as a tool to collect data in hard-to-include populations: Examples from paediatric oncology. BMC Research Methodology, 9, 15.

Varkey, P., Horne, A., \& Bennet, K. E. (2008). Innovation in health care: A primer. American Journal of Medical Quality, 23, 382-388.

Verkade, P-J., Van Meijel, B., Brink, C., Van Os-Medendorp, H., Koekoek, B., \& Francke, A. L.

(2010). Delphi-research exploring essential components and preconditions for case management in people with dementia. BMC Geriatrics, 10, 54.

Walston, J. T., \& Lissitz, R. W. (2000). Computer-mediated focus groups. Evaluation Review, 24, 457-483.

World Health Organisation (WHO). (2008). Guidance on developing quality and safety strategies with a health system approach. Geneva: WHO. Zwaanswijk, M., Tates, K., van Dulmen, S., Hoogerbrugge, P. M., Kamps, W. A., \& Bensing, J. M.

(2007). Young patients', parents', and survivors' communication preferences in paediatric oncology: Results of online focus groups. BMC Pediatrics, 7, 35.

Zwaanswijk, M., \& van Dulmen, S. (2014). Advantages of asynchronous online focus groups and faceto- face focus groups as perceived by child, adolescent and adult participants: A survey study. BMC Research Notes, 7 . 
Lange, J. de, Deusing, E., Asch, I.F. van, Peeters, J., Zwaanswijk, M., Pot, A.M., Francke, A.L.

Factors facilitating dementia case management: results of online focus groups. Dementia:

International Journal of Social Research and Practice: 2018, 17(1), 110-125

\section{TABLES}

Table I. Distribution and occupation of participants.

\begin{tabular}{|c|c|c|c|c|c|c|c|c|c|c|c|c|}
\hline Region & $N$ & $C M$ & GP & GPN & NRL & NU & NA & PL & PSY & MAN & LBY & WPM \\
\hline 1 & 6 & 3 & I & - & - & 2 & - & - & - & - & - & - \\
\hline 2 & 9 & 4 & 2 & I & 1 & - & - & - & - & 1 & - & - \\
\hline 3 & 10 & 4 & 1 & - & 3 & - & - & 2 & - & - & - & - \\
\hline 4 & 8 & 2 & - & - & - & 4 & I & I & - & - & - & - \\
\hline 5 & II & 6 & I & - & 1 & I & - & 2 & - & - & - & - \\
\hline 6 & 7 & 4 & - & - & 1 & 1 & - & I & - & - & - & - \\
\hline 7 & 9 & 3 & I & - & 3 & - & - & I & - & - & 1 & - \\
\hline 8 & 7 & I & 2 & - & 1 & 1 & - & I & I & - & - & - \\
\hline 9 & 4 & 2 & - & - & 1 & I & - & - & - & - & - & - \\
\hline 10 & II & 4 & - & - & 2 & 3 & - & - & 1 & - & - & 1 \\
\hline 11 & 4 & 2 & - & - & I & - & - & - & - & I & - & - \\
\hline 12 & 7 & 4 & - & - & - & 2 & - & 1 & - & - & - & - \\
\hline 13 & 6 & 3 & 1 & - & - & I & - & - & - & I & - & - \\
\hline Total & 99 & 42 & 9 & 1 & 14 & 16 & I & 9 & 2 & 3 & 1 & 1 \\
\hline
\end{tabular}

$\mathrm{N}$ : number of participants; CM: case manager; GP: general practitioner; GPN: general practice nurse; NRL: neurologist/ geriatrician; NU: nurse; NA: nursing assistant; PL: project-leader; PSY: psychologist; MAN: manager; LBY: lobbyist; WPM: welfare policymaker.

Table 2. Advantages of OFGs according to professionals $(N=22)$.

\begin{tabular}{llr}
\hline & $N$ & $\%$ \\
\hline I am able to participate at a moment most convenient to me & 22 & 100.0 \\
I can react from my own home and do not have to travel to participate & 19 & 86.4 \\
I prefer to give my answers anonymously & 2 I & 95.5 \\
I am better expressing my answers when I have to write them down & 18 & 81.8 \\
I find it easier to discuss personal issues through the Internet & 21 & 95.5 \\
Responding via Internet gives me more time to think about my answers & 1 I & 50.0 \\
\hline
\end{tabular}

